\title{
LENGTHENING OF SHORT GREAT TOES BY CALLUS DISTRACTION
}

\author{
YOSHINORI TAKAKURA， YASUHITO TANAKA， TADASHI FUJII， SUSUMU TAMAI
}

From Nara Medical University, Nara, Japan

We lengthened seven first metatarsals in four patients with short great toes by callus distraction using an external fixator. Good clinical and cosmetic results were obtained. Bone lengthening is effective in patients with short great toes not only for cosmesis, but also to relieve pain and callosities on the plantar aspect of the second and third metatarsal heads.

Excessive lengthening of the first metatarsal resulted in limitation of the range of movement of the metatarsophalangeal joint of the great toe. To prevent this the amount of lengthening should not exceed $40 \%$ of the preoperative length of the metatarsal.

J Bone Joint Surg [Br] 1997;79-B:955-8.

Received 2 May 1997; Accepted after revision 23 June 1997

Brachydactyly of the foot is a congenital deformity in which one or more toes are abnormally short due to a short metatarsal; the fourth toe is most commonly involved. ${ }^{1-3}$ First-ray insufficiency with shortening of the first metatarsal was first described as 'Morton's syndrome' or 'Morton's foot ${ }^{4}$ and becomes obvious in children at about ten years of age. The incidence is about one in 10000 ; in Japan one case was described in 10918 school children between 13 and 17 years of age. ${ }^{5}$

This deformity is not only cosmetically unacceptable but also impairs the weight-bearing mechanism of the foot. There is plantar pain, and the formation of callosities on the second and third metatarsal heads give difficulty in wearing high heels and in walking. $4,6,7$

We have performed bone lengthening by callus distraction (callotasis) with an external fixator on seven feet in

\begin{tabular}{l}
\hline Y. Takakura, MD, Associate Professor \\
Y. Tanaka, MD, Clinical Fellow \\
T. Fujii, MD, Clinical Fellow \\
S. Tamai, MD, Chairman and Professor \\
Department of Orthopaedic Surgery, Nara Medical University, Kashihara, \\
Nara 634, Japan. \\
Correspondence should be sent to Dr Y. Takakura. \\
\hline C1997 British Editorial Society of Bone and Joint Surgery
\end{tabular}

(C)1997 British Editorial Society of Bone and Joint Surgery

0301-620X/97/67933\$2.00

VOL. 79-B, No. 6, NOVEMBER 1997 four patients with a short great toe. We describe the operative procedure and our results.

\section{PATIENTS AND METHODS}

From 1989 to 1994 we treated 22 feet with short great toes in 14 patients conservatively with orthoses, including five with congenital club foot. Of these, seven feet in four patients had bone lengthening by callus distraction, three being treated bilaterally. All were women with a mean age of 21 years (20 to 23). Two had bilateral shortening of other toes. One (case 1) had shortened third and fourth toes and the other (case 2) shortened fourth toes. They all had pain under the second or third metatarsal heads when walking; in two patients callosities had formed under the affected metatarsal heads (Fig. 1). One patient (case 4) had pain on the medial side of the metatarsophalangeal (MTP) joint of the great toe with hallux valgus (Table I).

We used a standard dorsoplantar radiographic projection of the foot: the X-ray beam was inclined $15^{\circ}$ from the vertical at a distance of $100 \mathrm{~cm}^{8}$ We measured the length of the first and second metatarsals and expressed the length of the first as a percentage of the length of the second. The mean length of the first metatarsal was $65.8 \%$ (61.6 to 71.2). These values indicated severe shortening of the metatarsal, since the normal value is approximately $86 \%^{8}$ (Table I). Furthermore, the mean length of the great toe expressed as a percentage of the length of the second toe was $70.8 \%$ (68.3 to 72.6 ) which is shorter than the $83 \%$ of normal feet. ${ }^{8}$ Our patients therefore had a shortened metatarsal and proximal phalanx (Figs 1 and 2).

Operative technique. A longitudinal incision of about $3 \mathrm{~cm}$ is made on the dorsal side of the first metatarsal. The exposed periosteum is longitudinally incised and carefully stripped. Four pins, two at the proximal and distal sites, are inserted for external fixation and the cortex of the metatarsal bone is drilled between the second and third pins using a Kirschner wire. The bone is divided at the drill site with an osteotome, the periosteum and skin are sutured, and an external fixator (Orthofix M-fixator 100) attached.

The mean waiting period before the lengthening began was 12 days (11 to 14). One or two screws on the external fixator were turned by the patients themselves to obtain lengthening from $0.25 \mathrm{~mm}$ to $0.75 \mathrm{~mm}$ per day based on 


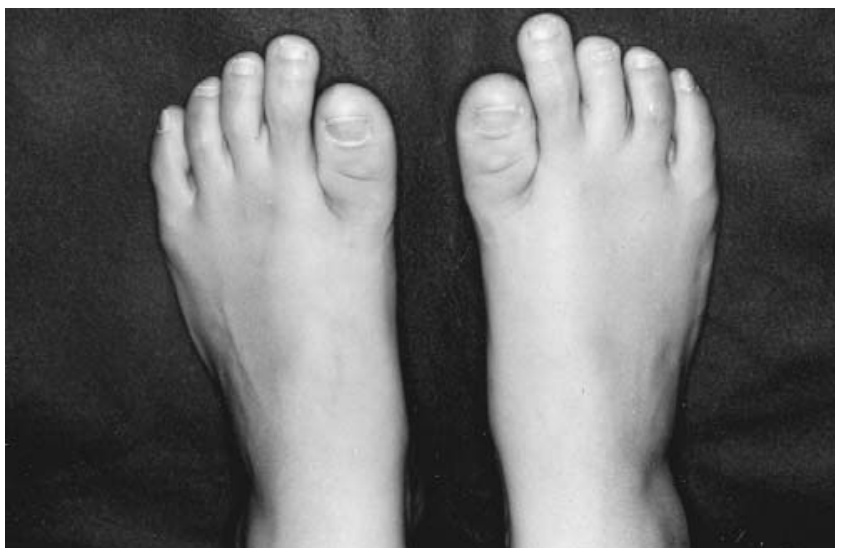

Fig. 1a

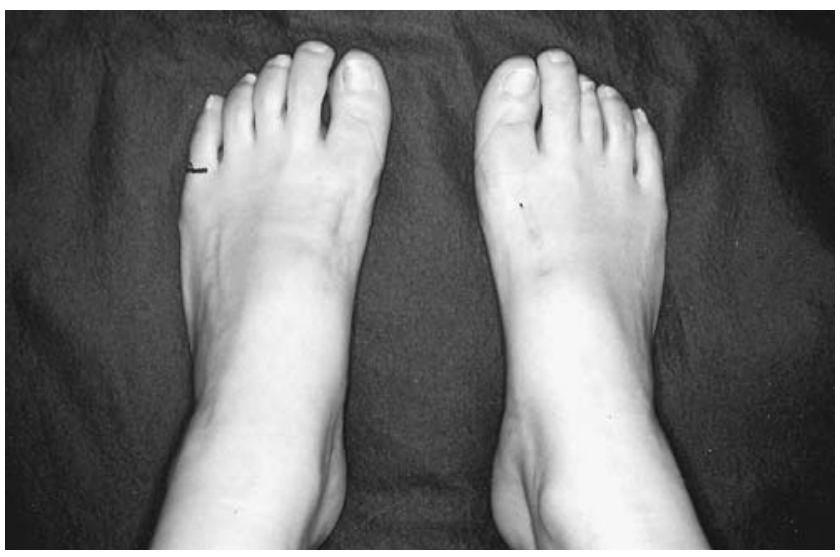

Fig. 1c

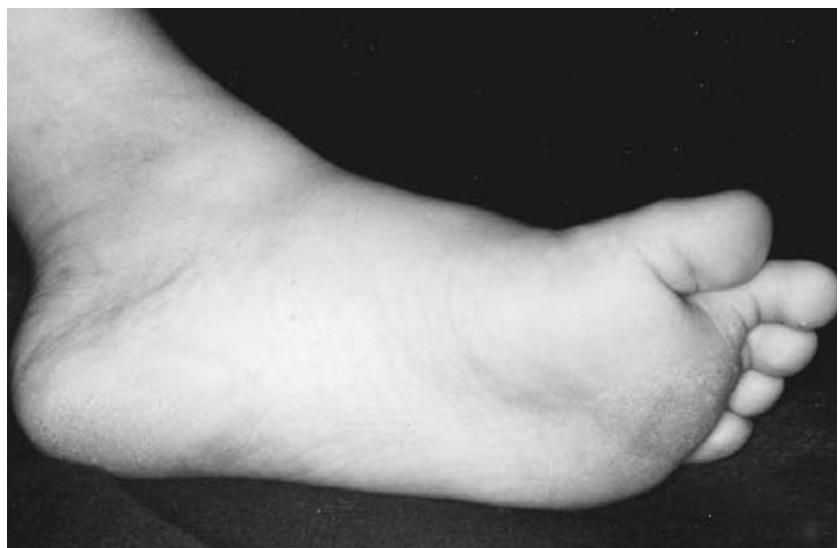

Fig. 1b

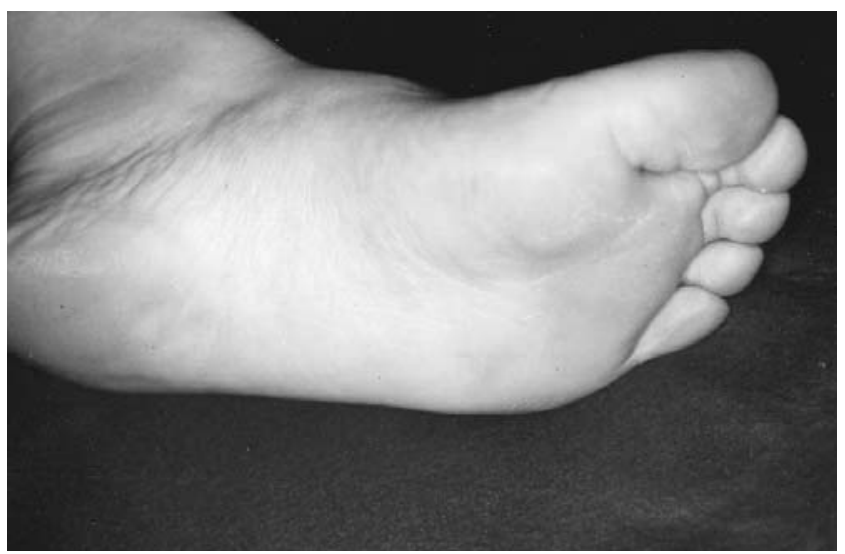

Fig. 1d

Case 3. Photographs showing bilateral shortening of the great toes (a), the sole of the foot with plantar callosities (b), both feet at 3 years 8 months after operation (c) and the disappearance of the plantar callosities (d).

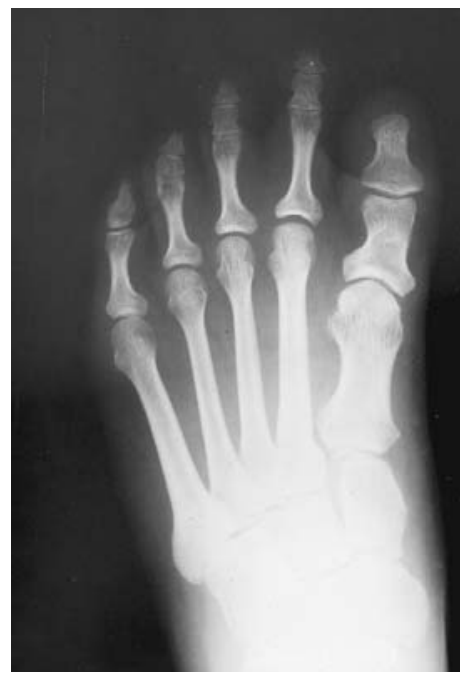

Fig. 2a

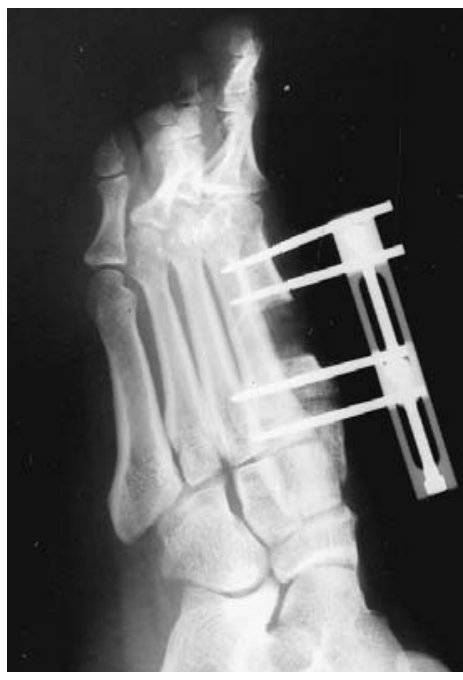

Fig. $2 b$

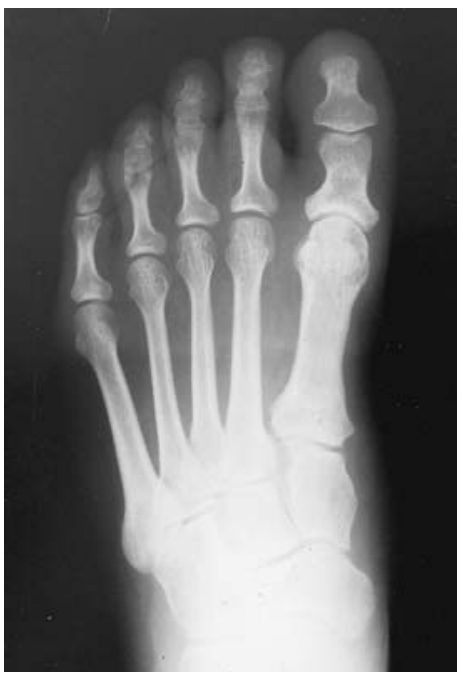

Fig. 2c

Case 3. Radiographs showing a left foot with shortening of the great toe before operation (a), during callus distraction five weeks after osteotomy (b) and at 3 years 8 months after operation (c). 
Table I. Details of four patients who had bone lengthening by callus distraction

\begin{tabular}{|c|c|c|c|c|c|c|c|c|c|c|c|c|c|c|c|}
\hline \multirow[b]{3}{*}{ Case } & \multirow[b]{3}{*}{ Sex } & \multirow{3}{*}{$\begin{array}{l}\text { Age } \\
(\mathbf{y r})\end{array}$} & \multirow[b]{3}{*}{ Side } & \multirow{3}{*}{$\begin{array}{l}\text { Other } \\
\text { deformity }\end{array}$} & \multirow{2}{*}{\multicolumn{2}{|c|}{ Plantar }} & \multirow{3}{*}{$\begin{array}{l}\text { Length } \\
\text { of first } \\
\text { metatarsal* } \\
(\%)\end{array}$} & \multirow{3}{*}{$\begin{array}{l}\text { Other } \\
\text { operations }\end{array}$} & \multirow{3}{*}{$\begin{array}{l}\text { Fixation } \\
\text { period } \\
(w k)\end{array}$} & \multirow{3}{*}{$\begin{array}{l}\text { Follow-up } \\
\text { (mth) }\end{array}$} & \multirow{2}{*}{\multicolumn{2}{|c|}{ Lengthening }} & \multirow{3}{*}{$\begin{array}{l}\text { Healing } \\
\text { index }\end{array}$} & \multicolumn{2}{|c|}{$\begin{array}{l}\text { Range of movement } \\
\text { MTP joint }\end{array}$} \\
\hline & & & & & & & & & & & & & & Preop & Postop \\
\hline & & & & & Pain & Callosity & & & & & $\mathbf{m m}$ & $\%$ & & $\mathbf{D F} / \mathbf{P F}$ & $\mathrm{DF} / \mathrm{PF}$ \\
\hline \multirow[t]{2}{*}{1} & $\mathrm{~F}$ & 21 & $\mathrm{R}$ & $\begin{array}{l}3 \text { and } 4 \\
\text { short }\end{array}$ & + & + & 66.5 & $\begin{array}{l}\text { One-stage } \\
\text { lengthening } \\
3 \text { and } 4 \\
\text { (bone graft) }\end{array}$ & 25 & 63 & 16.2 & 40.0 & 106.1 & $60 / 25$ & $30 / 15$ \\
\hline & & & $\mathrm{L}$ & $\begin{array}{l}3 \text { and } 4 \\
\text { short }\end{array}$ & + & + & 66.3 & $\begin{array}{l}\text { One-stage } \\
\text { lengthening } \\
3 \text { and } 4 \\
\text { (bone graft) } \\
\text { Shortening } \\
\text { of 2nd }\end{array}$ & 22 & 67 & 19.0 & 35.1 & 81.1 & $50 / 20$ & $25 / 10$ \\
\hline \multirow[t]{2}{*}{2} & $\mathrm{~F}$ & 20 & $\mathrm{R}$ & 4 short & + & - & 61.6 & $\begin{array}{l}\text { Lengthening } \\
4 \text { by callus } \\
\text { distraction }\end{array}$ & 15 & 58 & 16.5 & 32.4 & 63.6 & $50 / 20$ & $50 / 10$ \\
\hline & & & $\mathrm{L}$ & 4 short & + & - & 64.2 & $\begin{array}{l}\text { Lengthening } \\
4 \text { by callus } \\
\text { distraction }\end{array}$ & 10 & 55 & 13.5 & 25.7 & 51.9 & $55 / 25$ & $50 / 15$ \\
\hline \multirow[t]{2}{*}{3} & $\mathrm{~F}$ & 23 & $\mathrm{R}$ & - & + & - & 71.2 & - & 17 & 45 & 14.0 & 29.1 & 85.0 & $65 / 20$ & $40 / 10$ \\
\hline & & & $\mathrm{L}$ & - & + & + & 62.7 & - & 19 & 43 & 19.5 & 41.4 & 68.2 & $60 / 25$ & $30 / 10$ \\
\hline 4 & $\mathrm{~F}$ & 22 & $\mathrm{R}$ & $\begin{array}{l}\text { Hallux } \\
\text { valgus }\end{array}$ & + & - & 67.9 & $\begin{array}{l}\text { Mann's } \\
\text { osteotomy }\end{array}$ & 9 & 37 & 9.5 & 16.3 & 66.3 & $65 / 35$ & $45 / 20$ \\
\hline Mean & & 21.5 & & & & & 65.8 & & 16.7 & 52.6 & 15.5 & 31.4 & 74.6 & $58 / 24$ & $39 / 13$ \\
\hline
\end{tabular}

* see text

callus formation which was checked on radiographs each week. The usual rate of lengthening was $0.5 \mathrm{~mm}$ per day with continuous callus formation. Distraction was continued until the first metatarsal was at the same distal level as the head of the second metatarsal or there was severe limitation of the movement in the great toe.

All patients were allowed to walk with partial weightbearing on the day after the operation and were not immobilised in a cast or postoperative shoe. They used crutches only for two weeks.

\section{RESULTS}

Table I gives the details of the patients and the results. The mean period of lengthening was 16.7 weeks (9 to 25) which included the first waiting period, distraction and the neutralisation period. The mean lengthening was $15.5 \mathrm{~mm}$ (9.5 to $19.5)$ and the mean healing index, the number of days for $10 \mathrm{~mm}$ of lengthening, was 74.6 days (51.9 to 106.1$)$. The mean postoperative follow-up was 52.6 months (37 to 67).

No patient required bone grafting of the first metatarsal. In two patients (four feet) lengthening of toes other than the great toe was performed at the same time. One patient with unilateral hallux valgus (case 4) had bone lengthening and correction of the hallux valgus with excision of the exostosis and repair of the medial capsule at the same time.
The bone lengthening was successful, but the valgus correction was not satisfactory. This was revised by Mann's procedure, which does not shorten the first metatarsal, with a good result.

We measured movement of the first MTP joint with a goniometer on the medial side of the joint. There was a decrease of $33 \%$ in dorsiflexion and of $46 \%$ in plantar flexion (Table I). This showed the tendency for the range of movement to decrease inversely with the amount of lengthening of the metatarsal, but could not be confirmed statistically because of the small number of cases.

Postoperative complications included limited dorsiflexion of the great toe in two patients (three feet). One patient (case 1) complained of mild pain during dorsiflexion on the right side. Plantar callosities had been observed beneath the metatarsal heads of the second and third toes in three feet in two patients before the operation, but these disappeared within about six months after the operation (Fig. 1). All patients but one were able to wear heels of $5 \mathrm{~cm}$ and higher and to participate in sports, and all were satisfied with the cosmetic result.

\section{DISCUSSION}

The length of the first metatarsal in all our patients was much shorter than in the normal foot, and all had some pain 
on wearing high heels; two had plantar callosities (Fig. 1). Viladot $^{6}$ suggested that these symptoms indicate first-ray insufficiency, and noted that the weakness of the great toe causes abnormal weight-bearing with increased loading of the second ray. Treatment therefore requires lengthening of the first metatarsal of the great toe to restore natural weightbearing.

Our measurements showed that the mean length of the first metatarsal in affected feet was $65.8 \%$ (61.6 to 71.2) of that of the second metatarsal. This severe shortening, less than $75 \%$, compares with the $86 \%$ ratio for the normal foot. Furthermore, the mean length of the great toe was shorter than in $83 \%$ of normal feet. ${ }^{8}$ Most patients with a short first metatarsal have phalanges which are normal or longer, giving a smaller cosmetic problem. In the rare cases with shortening of the metatarsal and the phalanges, there is an obvious deformity. We believe symptoms and callosities develop when the length of the first metatarsal is less than $75 \%$ of the length of the second metatarsal.

All the patients in our series were able to walk on the second day after operation and had no pain during distraction. They were satisfied with the results of operative treatment in relieving cosmetic problems, pain and callosities.

There are many methods of lengthening the toes. Skirving and Newmann ${ }^{9}$ reported one case of lengthening of bone grafting after distraction. Other methods reported from Japan, where shortening of the fourth toe is common, include one-stage lengthening by bone graft, lengthening by interposed bone graft within the MTP joint, bone graft after gradual lengthening, and bone lengthening by callus distraction. $^{1-3,9}$ One-stage lengthening by bone graft is not recommended because muscles and tendons may become tethered. Gradual lengthening is preferable, and callus distraction without a bone graft is the best method. ${ }^{10}$ This requires only a short hospital stay and allows early walking with normal weight distribution. Callus formation is slower in the first metatarsal than in the lesser metatarsals, and distraction therefore takes longer. ${ }^{3}$ Another disadvantage is that scarring is worse than after one-stage lengthening because the four pins maintain skin tension for some time.

In two of our patients (three feet) postoperative limitations of dorsiflexion occurred because lengthening exceeded $40 \%$ of the preoperative length of the metatarsal. They both had difficulty wearing high heels. We therefore recommend that the rate of lengthening should not exceed $40 \%$ and that active and passive dorsiflexion should start soon after osteotomy.

No benefits in any form have been received or will be received from a commercial party related directly or indirectly to the subject of this article.

\section{REFERENCES}

1. Urano Y, Kobayashi A. Bone-lengthening for shortness of the fourth toe. J Bone Joint Surg [Am] 1978;60:91-3.

2. Wakisaka T, Yasui N, Kojimoto H, Takasu M, Shimomura Y. A case of short metatarsal bones lengthened by callus distraction. Acta Orthop Scand 1988;59:194-6.

3. Magnan B, Bragantini A, Regis D, Bartolozzi P. Metatarsal lengthening by callotasis during growth phase. J Bone Joint Surg [Br] 1995; 77-B:602-7.

4. Harris RI, Beath T. The short first metatarsal: its incidence and clinical significance. J Bone Joint Surg [Am] 1949;31-A:553-654.

5. Sugiura Y, Nakazawa O. Bone age: roentgen diagnosis of skeletal development. Tokyo, Chugai-Igaku, 1968:254-7.

6. Viladot A. Metatarsalgia due to biomechanical alterations of the forefoot. Orthop Clin North Am 1973;4:165-78.

7. Hughes J, Clark P, Klenerman L. The importance of the toes in walking. J Bone Joint Surg [Br] 1990;72-B:245-51.

8. Tanaka Y, Takakura Y, Kumai T, Samoto N, Tamai S. Radiographic analysis of hallux valgus: a two-dimensional coordinate system. J Bone Joint Surg [Am] 1995;77-A:205-13.

9. Skirving AP, Newman JH. Elongation of the first metatarsal. J Pediatr Orthop 1983;3:508-10.

10. De Bastiani G, Aldegheri R, Renzi-Brivio L, Trivella G. Limb lengthening by callus distraction (callotasis). J Pediatr Orthop 1987;7: 129-34. 